\title{
Pemanfaatan Data Pasang Surut Stasiun Meteorologi dan Maritim untuk Identifikasi Kenaikan Muka Air Laut Kota Pontianak
}

\author{
Mochammad Meddy Danial ${ }^{1}$, Darmania ${ }^{2}$, Nanda Purnama Sari ${ }^{3)}$ \\ ${ }^{1)}$ Dosen Jurusan Teknik Kelautan, Universitas Tanjungpura,Pontianak, Indonesia \\ ${ }^{213)}$ Mahasiswa Jurusan Teknik Kelautan, Universitas Tanjungpura, Pontianak, Indonesia \\ Corresponding Author: Mochammad Meddy Danial, meddydanial@civil.untan.ac.id
}

\begin{abstract}
Abstrak: Kota Pontianak terletak pada daerah dataran rendah, sehingga sangat rentan terhadap genangan banjir akibat air laut pasang. Tulisan ini bertujuan untuk memanfaatkan dan menganalisis data pasang surut untuk mengidentifikasi kenaikan muka air laut dan membakukan satuan muka air pasang surut. Data pasang surut jam-jaman diperoleh dari Stasiun Meteorologi Maritim Pontianak. Panjang data satu tahun diolah dengan metode analisa harmonik untuk mendapatkan konstanta pasang surut, untuk tahun 2016 dan 2020. Nilai konstanta tersebut akan digunakan untuk mengidentifikasi kenaikan muka air laut dengan cara menghitung tinggi muka air maksimum, tinggi muka air rata-rata, dan tinggi muka air minimum. Untuk membakukan data elevasi muka air pasang surut, dilakukan konversi elevasi tinggi palm pasang surut menjadi satuan meter LWS dengan menggunakan waterpas untuk menghitung beda tinggi dengan elevasi lantai dermaga 01 Pelindo. Hasil analisis menunjukkan indikasi kenaikan muka air laut, dimana tinggi muka air laut rata-rata berubah dari $1.54 \mathrm{~m} \mathrm{LWS} \mathrm{pada}$ tahun 2016 menjadi 1.66 m LWS pada tahun 2020. Hasil nilai muka air maksimum adalah $2.6 \mathrm{~m}$ LWS dan hasil nilai muka air minimum adalah $0.93 \mathrm{~m} \mathrm{LWS}$. Beda tinggi antara elevasi puncak palm pasang surut dengan lantai dermaga menunjukkan perbedaan $+0.810 \mathrm{~m}$. Dengan demikian, elevasi puncak palm pasang surut setara dengan $+3.0 \mathrm{~m}$ LWS, jika diukur dari lantai dermaga Pelindo.
\end{abstract}

Kata Kunci: Pasang surut, kenaikan muka air laut, konversi elevasi palm.

\begin{abstract}
Pontianak city is located in a low-lying area which is vulnerable to the flood event due to high tides. This paper aims to utilize and analyze the time series of tidal data to cope identify sea level rise and standardize the unit of tidal elevation. Hourly tidal data was obtained from the Maritime Meteorology Station, Pontianak. The one year length of data was evaluated using the harmonic analysis method to obtain the parameter of tidal constants for year 2016 and 2020. This constant value will be used to identify sea level rise by calculating the maximum water level, average water level, and minimum water level. In order to standardize, conversing the tidal pole crest elevation into the unit of meters LWS was carried out by using a waterpass instrument to calculate the height differences between the crest of tidal pole and the pier floor 01 of Pelindo. The result indicates an increasing of sea level, where the average of sea level changes from $1.54 \mathrm{~m} \mathrm{LWS}$ in 2016 to $1.66 \mathrm{~m}$ LWS in 2020. The maximum water level value is $2.6 \mathrm{mLWS}$ and the minimum water level value is $0.93 \mathrm{mLWS}$. The height differences between the elevation of the tidal pole crest and the pier floor is $+0.810 \mathrm{~m}$. Thus, the elevation of the tidal palm crest is equivalent to +3.0 m LWS, when measured from the Pelindo pier floor.
\end{abstract}

Keywords:Tides, sea level rise, conversion of tide pole crest elevation.

Submited: 19-08-2021 Revised 07-10-2021 Accepted: 12-10-2021 


\section{Pendahuluan}

Kota Pontianak yang terletak di daerah delta Kapuas, rentan terhadap berbagai bencana hidrometeorologi, contohnya bencana banjir, intrusi air asin, dan perambatan gelombang pasang surut. Secara hidrotopografi, Pontianak mempunyai kontur topografi yang cukup datar dan rendah (lowland area), yaitu mempunyai ketinggian permukaan tanah antara $0.1-1.5 \mathrm{~m}$ di atas permukaan air laut (Diskominfo, 2019). Kondisi tersebut menyebabkan Pontianak mudah mengalami genangan air periodik dari pengaruh pasang surut, sebagai konsekuensi logis dari apa yang disebut dengan kota sungai (river front city) dan kota pantai (water front city) (Danial dkk., 2004). Kondisi genangan ini diperparah jika bersamaan dengan musim hujan, yang menyebabkan problem banjir perkotaan semakin kompleks (Diskominfo, 2019).

Kombinasi banjir akibat pasang surut dari laut dan debit hujan dari hulu merupakan bahaya gabungan untuk daerah Pontianak dan wilayah kabupaten/kota pesisir lainnya, yang dapat berdampak pada kondisi demografi, mata pencaharian, dan sosial ekonomi (Pratama dkk., 2017). Sejak September 2019 hingga saat ini, Kota Pontianak relatif mengalami hujan sepanjang tahun yang menyebabkan frekuensi kejadian banjir parah menjadi sering, sebagai akibat dari pengaruh fenomena La Nina (Liberto, 2021).

Inisiatif program pemerintah dalam penanggulangan banjir kota Pontianak sudah banyak dilakukan, namun sayangnya belum terdapat suatu sistem keseragaman data terhadap elevasi atau ketinggian muka air laut yang dapat digunakan sebagai titik referensi (bench mark) yang dapat diandalkan (Bappenas, 2020). Konversi satuan muka air laut menjadi satuan meter Low water spring (m LWS) adalah solusi dalam memecahkan permasalahan tersebut. Untuk itu, pembuatan standar tunggal ketinggian muka air laut menjadi pekerjaan rumah yang harus diselesaikan.

Stasiun Meteorologi Maritim Pontianak adalah institusi strategis yang bertanggungjawab melakukan pengamatan, pengelolaan data, dan pelayanan informasi meteorologi di wilayah Pontianak dan Kalimantan Barat. Data-data pada instansi pemerintah tersebut bisa dimanfaatkan dan diberdayakan, diantaranya untuk menganalisis perilaku hidrodinamika interaksi aliran antara hulu sungai dan muara (Danial dkk., 2020). Salah satu data penting yang akan dimanfaatkan dan diberdayakan adalah data time series pasang surut yang diukur dan dicatat dengan interval waktu tertentu. Data pasang surut yang diolah juga bisa dimanfaatkan untuk mengidentifikasi terjadinya kenaikan muka air laut akibat perubahan iklim (climate change) dan dapat digunakan memprediksi kenaikan muka air laut pada tahun yang akan datang dengan menggunakan metode regresi linier (Sihombing dkk., 2012).

Tulisan ini bertujuan mengolah dan menganalisis data pasang surut untuk mengevaluasi elevasi muka air laut, menginvestigasi adaya indikasi kenaikan muka air laut, dan mengkonversi elevasi pasang surut menjadi satuan standar tunggal, yang dapat dijadikan referensi hidrografi secara resmi oleh seluruh institusi pemerintahan terkait di Pontianak.

\section{Metodologi}

Data pasang surut diperoleh dari Stasiun Meteorologi Maritim Pontianak. Pasang surut yang dianalisis berupa data jam-jaman dengan panjang data selama satu tahun, yaitu untuk tahun 2016 dan 2020. Penggunaan gabungan perangkat lunak T-Tide dan metode Least Square digunakan untuk mendapatkan konstanta pasang surut, sehingga diperoleh nilai tinggi muka air maksimum (high water spring atau $H W S$ ), muka air rata-rata (mean sea level atau $M S L$ ), dan muka air minimum (low water spring atau $L W S$ ) (Guo et al., 2015; Lu et al., 2015). Nilai $H W L$, $M S L$, dan $L W S$ akan digunakan untuk mengevaluasi elevasi muka air laut. Sedangkan nilai-nilai MSL tahun 2016 dan 2020 akan digunakan untuk mengidentifikasi kenaikan muka air laut 
(Devlin et al ., 2017; Manurung, 2004). Kemudian kedua data untuk tahun 2016 dan 2020 tersebut akan dibandingkan untuk mengetahui adanya kenaikan muka air laut.

Untuk menstandarkan elevasi muka air pasang surut agar dapat dijadikan referensi tunggal dalam perencanaan mitigasi banjir kota Pontianak, maka dilakukan pengukuran konversi elevasi puncak palm pasang surut Stasiun Meteorologi Maritim menjadi satuan meter LWS (m $L W S$ ) dengan menggunakan waterpas untuk menghitung beda tinggi dengan elevasi lantai dermaga 01 Pelindo (Mutiara dan Muhiddin, 2016). Metode pengukuran beda tinggi dan analisanya, diilustrasikan pada Gambar 1.

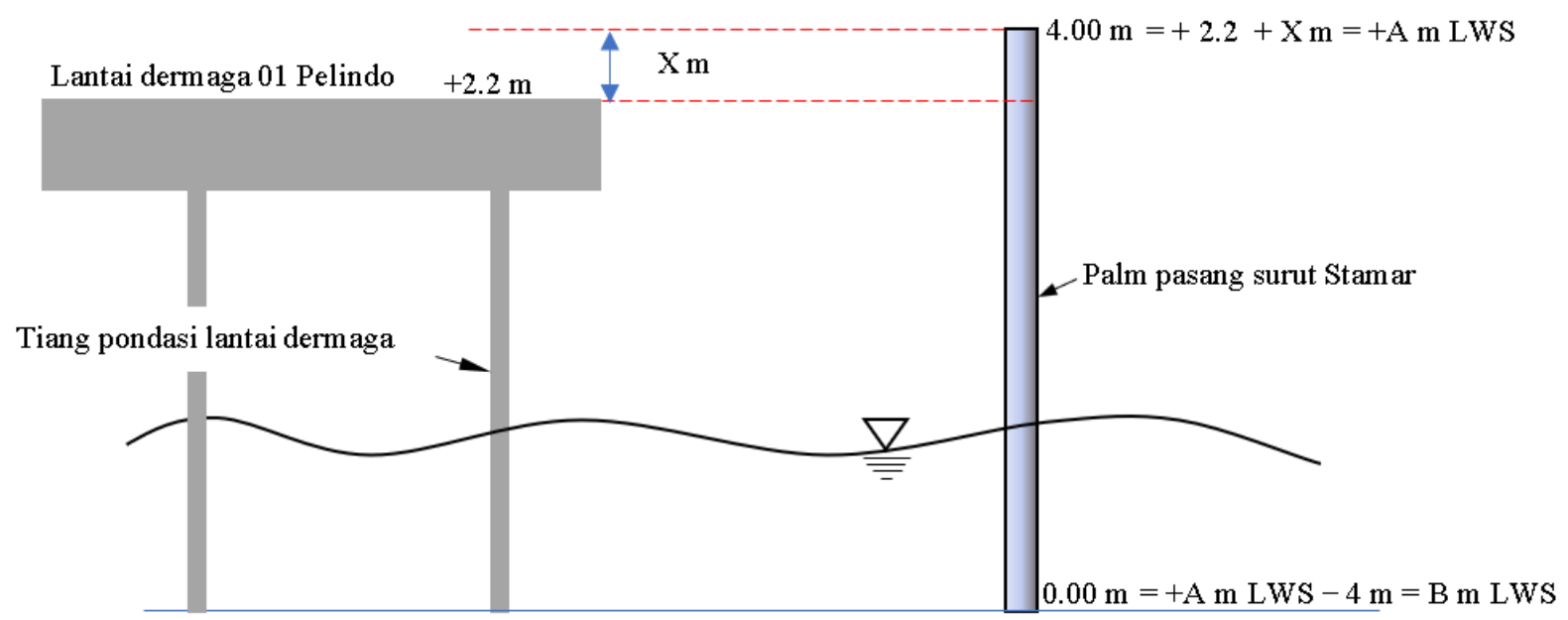

Gambar 1. Metode konversi muka air pasang surut dengan satuan meter LWS lantai dermaga Pelindo 01

Pengukuran beda tinggi terhadap palm pasang surut (tidal gauge) menggunakan waterpas dilakukan pada beberapa titik di lantai dermaga 01 Pelindo. Kemudian dari hasil hitungan, dilakukan perata-rataan nilai akhir. Posisi titik-titik pengukuran pada lantai dermaga dan palm pasang surut dapat dilihat pada Gambar 2.

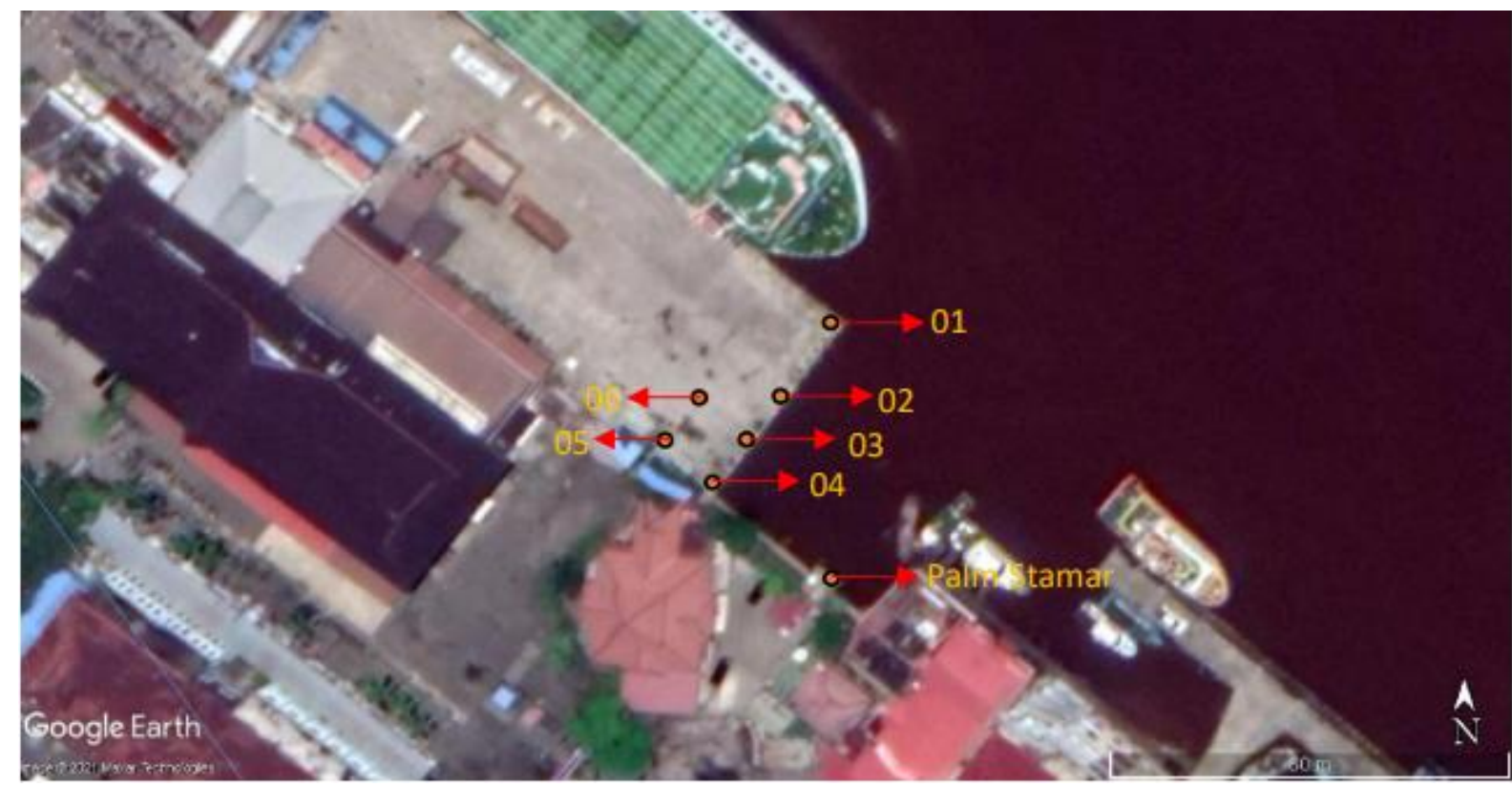

Gambar 2. Posisi titik-titik pengukuran waterpas terhadap palm pasang surut 


\section{Hasil dan Pembahasan}

\section{A. Hasil}

Gambar 3 menunjukkan pola pasang surut jam-jaman pada tahun 2016 dan tahun 2020. Secara visual, perbandingan pola variasi muka air laut pasang surut pada tahun 2016 terlihat berbeda dengan tahun 2020, dimana elevasi muka air maksimum pada tahun 2020 lebih tinggi dibanding data tahun 2016.
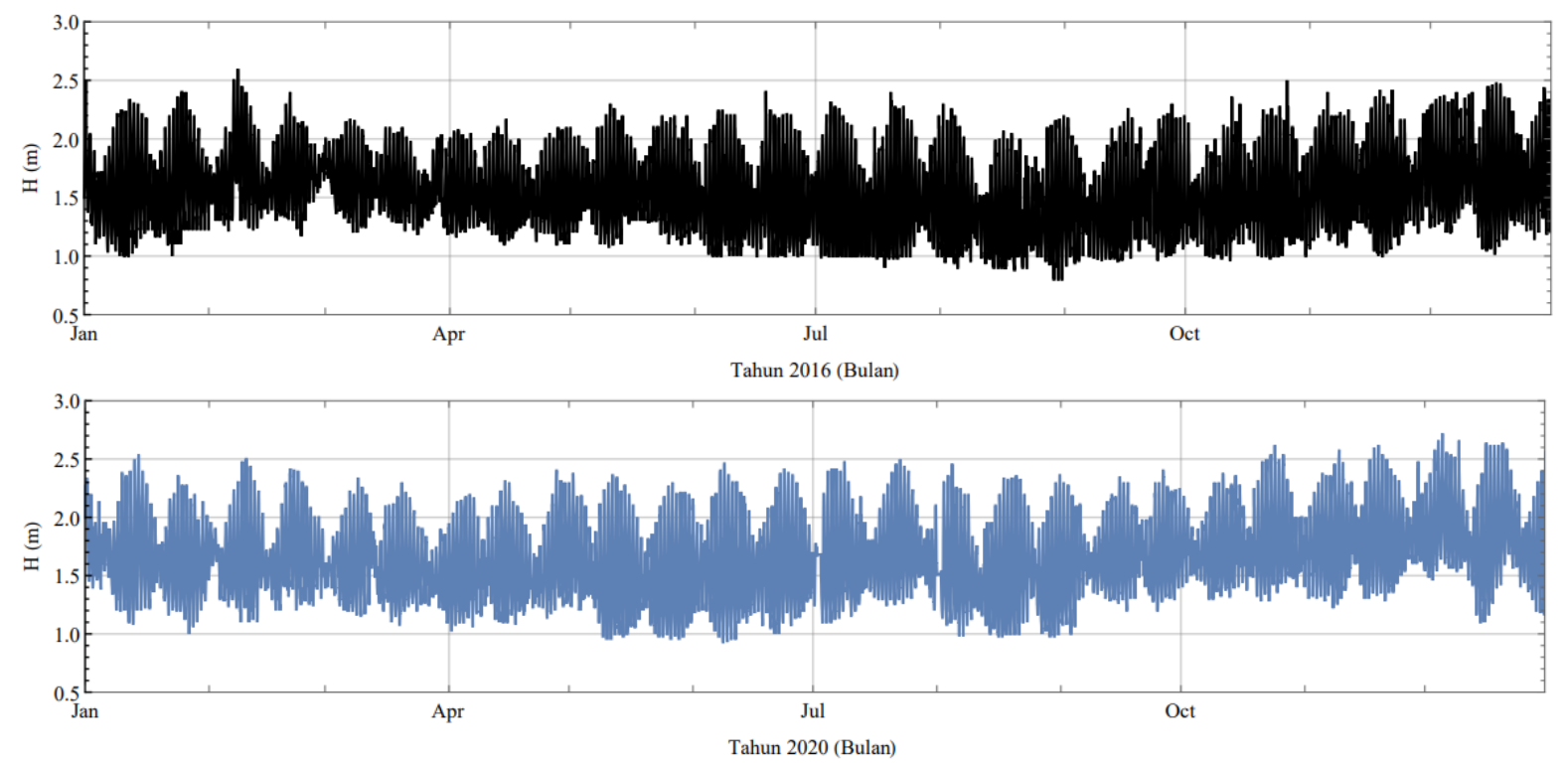

Gambar 3. Pola pasang surut Tahun 2016 (atas) dan Tahun 2020 (bawah).

Data pada Gambar 3 dianalisis dengan software T-Tide dan metode Least Square untuk mendapatkan konstanta amplitudo pasang surut yang dapat digunakan untuk menghitung nilai MSL, HWL, dan LWS. Hasil evaluasi muka air untuk tahun 2016 dan 2020 dapat dilihat pada Tabel 1 dan perhitungan karakteritik pasang surut dapat dilihat pada Tabel 2. Perhitungan karakteristik diperlukan untuk mengkonfirmasi sifat pasang surut kota Pontianak yang berguna dalam mengatasi kenaikan muka air laut di wilayah kota Pontianak.

Tabel 1. Hasil perhitungan elevasi muka air dengan metode Least-square.

\begin{tabular}{ccr} 
Elevasi muka air & Tahun 2016 & Tahun 2020 \\
\hline HWS & 2.60 & 2.62 \\
MSL & 1.54 & 1.66 \\
LWS & 0.8 & 0.93 \\
\hline
\end{tabular}

Tabel 2. Hasil perhitungan bilangan Formzahl.

\begin{tabular}{crr} 
Konstanta & Tahun 2016 & Tahun 2020 \\
\hline K1 & 0.3532 & 0.3097 \\
O1 & 0.2657 & 0.2436 \\
M2 & 0.1288 & 0.1225 \\
S2 & 0.0503 & 0.0489 \\
F & 3.455611 & 3.228121 \\
\hline
\end{tabular}


Nilai bilangan Formzahl (F) dari hasil analisis Tabel 2 adalah 3.45 dan 3.22 untuk tahun 2016 dan 2020, berturut-turut, yang maknanya adalah jenis pasang surut kota Pontianak bertipe pasang surut harian tunggal (diurnal tide), yaitu dalam satu hari (24 jam) terjadi satu kali pasang dan satu kali surut.

Hasil nilai MSL tiap bulan untuk tahun 2016 dan 2020 ditabulasikan dan dibandingkan dalam bentuk seperti Tabel 3. Untuk lebih mempermudah mengidentifikasi pola variasi kenaikan muka air laut, data pada Tabel 3 tersebut diilustrasikan dalam bentuk grafik yang dapat dilihat pada Gambar 4.

Tabel 3. Muka air rata-rata bulanan

\begin{tabular}{cccccccccccccc}
\hline Tahun & 1 & 2 & 3 & 4 & 5 & 6 & 7 & 8 & 9 & 10 & 11 & 12 & Rata-rata \\
\hline 2016 & 1.59 & 1.69 & 1.60 & 1.52 & 1.57 & 1.48 & 1.46 & 1.36 & 1.45 & 1.48 & 1.62 & 1.70 & 1.54 \\
2020 & 1.67 & 1.66 & 1.57 & 1.57 & 1.53 & 1.57 & 1.67 & 1.53 & 1.66 & 1.75 & 1.81 & 1.85 & 1.66 \\
\hline
\end{tabular}

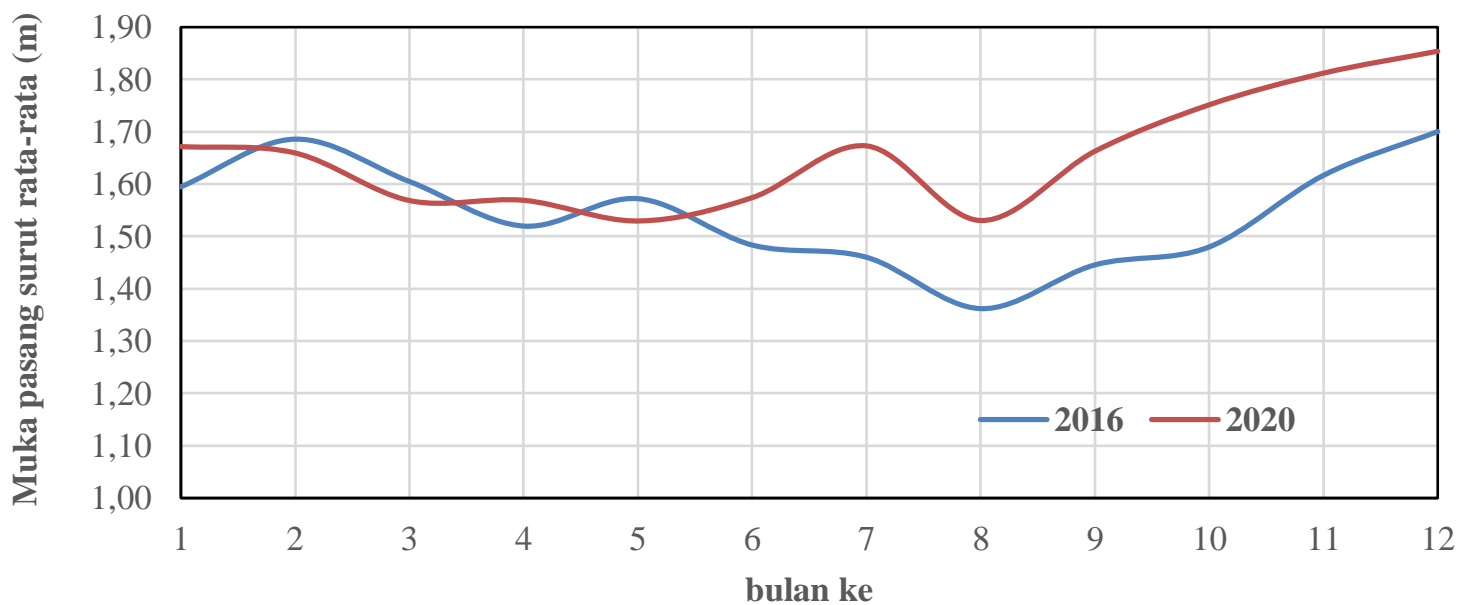

Gambar 4. Muka pasang surut rata-rata bulanan Tahun 2016 dan Tahun 2020.

Data hasil pengukuran lapangan untuk beda tinggi antara elevasi palm pasang surut dengan enam titik lokasi pada lantai dermaga 01 Pelindo, menggunakan alat ukur waterpas, dapat dilihat pada Tabel 4.

Tabel 4. Hasil pengukuran beda tinggi palm pasut terhadap elevasi 01 dermaga Pelindo

\begin{tabular}{lr} 
Posisi Titik Pengukuran & Beda Tinggi \\
\hline Palm Pasang Surut Stamar & 0 \\
Titik 01 Lantai Dermaga Pelindo & -0.813 \\
Titik 02 Lantai Dermaga Pelindo & -0.7475 \\
Titik 03 Lantai Dermaga Pelindo & -0.784 \\
Titik 04 Lantai Dermaga Pelindo & -0.864 \\
Titik 05 Lantai Dermaga Pelindo & -0.869 \\
Titik 06 Lantai Dermaga Pelindo & -0.7835 \\
Beda tinggi rata-rata & -0.810 \\
\hline
\end{tabular}




\section{B. Pembahasan}

Hasil evaluasi elevasi muka air pasang surut berbeda dengan hasil evaluasi dari instansi lain (Dinas PUPR) untuk nilai tinggi air maksimum, sedangkan untuk perhitungan tinggi muka air rata-rata (MSL) mempunyai hasil yang sama. Perbedaan ini bisa terjadi, kemungkinan karena perbedaan panjang data yang digunakan. Semakin panjang data pasang surut yang digunakan, hasilnya akan semakin akurat.

Hasil investigasi kenaikan air laut menunjukkan adanya indikasi kenaikan muka air laut dengan nilai MSL 1.54 m pada tahun 2016 menjadi nilai MSL $1.66 \mathrm{~m}$ pada tahun 2020. Artinya terjadi kenaikan muka air laut sebesar $0.12 \mathrm{~m}$ dalam kurun waktu empat tahun. Kenaikan muka air laut ini kemungkinan disebabkan oleh faktor pemanasan suhu bumi global (global warming) yang mengakibatkan perubahan iklim (climate change). Ada dua akibat langsung dari perubahan iklim, yaitu: terjadinya pencairan es di daratan kutub utara yang mengakibatkan kenaikan muka air laut global sekitar $0.03 \mathrm{~m}$; dan terjadinya perubahan siklus hidrologi yang menyebabkan peningkatan curah hujan eksrim, yang secara linier memberikan penambahan pada volume air laut global (Howard dkk., 2014).

Proses standarisasi elevasi muka air laut dari palm pasang surut dengan lantai dermaga 01 Pelindo menunjukkan bahwa puncak palm dengan elevasi $4 \mathrm{~m}$ adalah setara dengan +3.01 $\mathrm{m}$ LWS atau bisa dibulatkan menjadi +3.0 m LWS, sebagaimana terlihat pada Gambar 1 .

\section{Simpulan}

Pemberdayaan dan pemanfaatan data pasang surut dari Stasiun Meteorologi Maritim Pontianak berhasil dikompilasi dan dianalisis untuk menghasilkan luaran yang dapat digunakan untuk mengidentifikasi adanya kenaikan muka air laut, dalam rentang periode tahun 2016 dan 2020. Indikatornya, terjadinya peningkatan nilai MSL dari tahun 2016 ke tahun 2020. Selain itu, kegiatan PKM ini berhasil mengkonversi palm pasang surut menjadi satuan $\mathrm{m}$ LWS. Indikatornya adalah dapat dihitungnya beda elevasi antara puncak palm pasang surut dengan lantai dermaga 01 Pelindo. Dengan demikian, standarisasi elevasi muka air pasang surut berhasil dilakukan untuk menjadi acuan baku yang resmi bagi seluruh instansi pemerintahan terkait di kota Pontianak untuk perencanaan pembangunan infrastrukur yang optimal dalam mengatasi kenaikan muka air laut di kota Pontianak.

\section{Ucapan Terima Kasih}

Paper ini merupakan luaran dari kegiatan pengabdian kepada masyarakat Jurusan Teknik Kelautan dari pembiayaan DIPA Fakultas Teknik Universitas Tanjungpura dengan Nomor Kontrak: 3195/UN22.4/KU/2021. Kami juga mengucapkan terima kasih kepada Kepala Stasiun Meteorologi Maritim Pontianak dalam penyediaan data pasang surut berdasarkan Perjanjian Kerjasama (PKS) dengan Jurusan Teknik Kelautan Nomor 2915/UN22.4/KS/2021 dan Nomor HM.02.02/004a/KPTK/VI/2021. Terima kasih diucapkan kepada General Manager Pelindo dalam kegiatan pengukuran lapangan di dermaga 01.

\section{Daftar Pustaka}

Bappenas. (2020). Membangun Kota Tangguh Banjir: pendekatan terpadu untuk pembangunan berkelanjutan. Jakarta.

Danial, M. M., Herawati, H., Budiman, F., \& Ramdani. (2020). Dynamic interaction between tidal current and upstream discharge at the Kapuas River mouth. In 2nd International Conference on Green Energy and Environment (ICoGEE (hal. 7). IOP Publishing. https://doi.org/10.1088/1755-1315/599/1/012073 
Danial, M. M., Soeryamassoeka, S. B., \& Azwansyah, H. (2004). Penentuan Lokasi Banjir Tertinggi Kota Pontianak Dengan Pendekatan Matematis Linier. Pontianak.

Devlin, A. T., Jay, D. A., Talke, S. A., Zaron, E. D., Pan, J., \& Lin, H. (2017). Coupling of sea level and tidal range changes, with implications for future water levels. Scientific Reports, 7(1), 1-12. https://doi.org/10.1038/s41598-017-17056-z

Diskominfo. (2019). Masterplan Pontianak Smart City Tahun 2019-2029. Pontianak, Indonesia: Pemkot Pontianak.

Guo, L., Van Der Wegen, M., Jay, D. A., Matte, P., Wang, Z. B., Roelvink, D., \& He, Q. (2015). River-tide dynamics: Exploration of nonstationary and nonlinear tidal behavior in the Yangtze River estuary. Journal of Geophysical Research C: Oceans, 120(5), 3499-3521. https://doi.org/10.1002/2014JC010491

Howard, T., Ridley, J., Pardaens, A. K., L. Hurkmans, R. T. W., Payne, A. J., Giesen, R. H., ... Oerlemans, J. (2014). The land-ice contribution to 21 st-century dynamic sea level rise. Ocean Science, 10(3), 485-500. https://doi.org/10.5194/os-10-485-2014

Liberto, T. Di. (2021). La NIna. Diambil dari https://www.climate.gov/newsfeatures/blogs/enso/july-2021-enso- update-la-niña-watch\%0ALinks

Lu, S., Tong, C., Lee, D. ., Zheng, J., Shen, J., Zhang, W., \& Yan, Y. (2015). Propagation of tidal waves up in Yangtze Estuary during the dry season. Journal of Geophysical Research: Oceans, 120(9), 6445-6473. https://doi.org/10.1002/2014JC010414

Manurung, P. (2004). Permanent Sea Level Monitoring in Indonesia. GLOSS Training, (February), 1-11. Diambil dari https://www.glosssealevel.org/sites/gloss/files/publications/documents/indonesia2006.pdf

Mutiara, I., \& Muhiddin, A. H. (2016). Pengamatan Pasang Surut Untuk Penentuan Datum Ketinggian Di Pantai Desa Parak, Kecamatan Bonto Matene, Kabupaten Selayar, Provinsi Sulawesi Selatan. Spermonde, 2, 44-46.

Pratama, A. Y., Kusnandar, D., \& Debataraja, N. N. (2017). Analisis Dampak Kenaikan Muka Air Laut Di Kabupaten Kubu Raya Dan Kabupaten Mempawah Dengan Metode Analytical Hierarchy Process (AHP). Buletin Ilmiah Math. Stat. dan Terapannya, 6(03), $167-176$.

Sihombing, W. H., Suntoyo, \& Sambodho, K. (2012). Kajian Kenaikan Muka Air Laut di Kawasan Pesisir Kabupaten Tuban Jawa Timur. Teknik Sipil, 1, 6-9. 